\title{
Examining the impact of deep learning technology capability on manufacturing firms: moderating roles of technology turbulence and top management support
}

\author{
Sheshadri Chatterjee ${ }^{1}$ (D) Ranjan Chaudhuri ${ }^{2}$ (D) Demetris Vrontis ${ }^{3}$. \\ Thanos Papadopoulos 4
}

Accepted: 15 December 2021

(c) The Author(s), under exclusive licence to Springer Science+Business Media, LLC, part of Springer Nature 2021

\begin{abstract}
Data science can create value by extracting structured and unstructured data using an appropriate algorithm. Data science operations have undergone drastic changes because of accelerated deep learning progress. Deep learning is an advanced process of machine learning algorithm. Its simple process of presenting data to the system is sharply different from other machine learning processes. Deep learning uses advanced analytics to solve complex problems for accurate business decisions. Deep leaning is considered a promising area for creating additional value in firms' productivity and sustainability as they develop their smart manufacturing activities. Deep learning capability can help a manufacturing firm's predictive maintenance, quality control, and anomaly detection. The impact of deep learning technology capability on manufacturing firms is an underexplored area in the literature. With this background, the purpose of this study is to examine the impact of deep learning technology capability on manufacturing firms with moderating roles of deep learning related technology turbulence and top management support of the manufacturing firms. With the help of literature review and theories, a conceptual model has been prepared, which is then validated with the PLS-SEM technique analyzing 473 responses from employees of manufacturing firms. The study shows the significance of deep learning technology capability on smart manufacturing
\end{abstract}

$凶$ Ranjan Chaudhuri ranjan@nitie.ac.in

Sheshadri Chatterjee

sheshadri.academic@gmail.com

Demetris Vrontis

vrontis.d@unic.ac.cy

Thanos Papadopoulos

A.Papadopoulos@kent.ac.uk

1 Department of Computer Science and Engineering, Indian Institute of Technology Kharagpur, Kharagpur, West Bengal, India

2 Department of Marketing, National Institute of Industrial Engineering (NITIE), Mumbai, India

3 Faculty and Research, Strategic Management, School of Business, University of Nicosia, Nicosia, Cyprus

4 Kent Business School, University of Kent, Kent, UK 
systems. Also, the study highlights the moderating impacts of top management team (TMT) support as well as the moderating impacts of deep learning related technology turbulence on smart manufacturing systems.

Keywords Deep learning - Data science - Predictive maintenance - Anomaly detection · Smart manufacturing system

\section{Introduction}

Firms' operations mostly depend on available datasets, which they rely on data science to analyze (Wang et al., 2021). Data science is considered an inter-disciplinary field, and it is now experiencing a quantum shift with the arrival of deep learning technology. Deep learning is a subset of machine learning, which is, in turn, a subset of artificial intelligence (Wu et al., 2020). Deep learning uses multiple layers to extract valuable information from structured, semi-structured, and even from unstructured data.

Gradually, deep learning is gaining importance, as it exhibits supremacy over machine learning related to efficient predictive performance (Guan et al., 2019; LeCun et al., 2015). Deep learning can handle various types of datasets, which might be structured, semistructured, or even unstructured data, and it can solve a problem through a single action (Schmidhuber, 2015). According to Grand View Research Report, 37\% of manufacturing firms are using deep learning capabilities in their processes, products, and services. The market of deep learning technology is growing rapidly, and it is forecast that the market of deep learning technology in the USA will reach $\$ 10.2$ billion by 2025 (Grand View Research, 2017). A manufacturing firm's deep learning capability can help it towards predictive maintenance, quality control, as well as anomaly detection (Bromuri et al., 2020; Liu et al., 2020).

Deep learning technology is a comparatively new technology (Aruna Santhi \& Vijaya Saradhi, 2021), and when manufacturing firms use it, there is a chance that stakeholders will resist it, and frequent upgrades of the technology invites the concept of technology turbulence (Xiao et al., 2020), which is the rate of change of technology in a manufacturing firm (Song et al., 2005). Nevertheless, deep learning technology can improve a manufacturing firm's performance provided the top management extends effective support to using it (Adebowale et al., 2020). Studies have demonstrated how deep learning ability of a manufacturing firm could help the firm for its quality control, predictive maintenance along with appropriate detection of anomaly (Chen et al., 2021; Liu et al., 2020). Studies are found to have documented that for effective predictive performance, deep learning technology could supersede the effectiveness of machine-learning applications in this context (Guan et al., 2019; Wong et al., 2021). Studies have also documented how deep learning ability with the help of depthwise neural network could detect COVID-19 infection and its appropriate diagnosis (Qayyum et al., 2021). However, studies concerning the attempts to identify the determinants of deep learning capability which could influence the smart manufacturing system under the moderating impacts of technology turbulence as well as top management support are found to be in rudimentary stage. In this background, the aim of this study is to address the following objectives.

(i) To determine the different components of deep learning technology capability for smart manufacturing.

(ii) To examine the impact of deep learning technology capability on manufacturing firms. 
(iii) To investigate the moderating impact of technology turbulence and top management support on manufacturing firms.

The remaining structure of the paper is arranged as follows. Section 2 represents the literature review, followed by the discussion on the theoretical background and development of a conceptual model in Sect. 3. After that, in Sect. 4, research methodology is described in detail. Next, data analysis and results are presented in Sect. 5, followed by the discussion on the results in Sect. 6, which also contains the theoretical contributiond and practical implications, along with discussions on limitations with future scope for researchers.

\section{Literature review}

Deep learning can be considered as a subset of machine learning, and machine learning is considered as a subset of artificial intelligence (AI). Deep learning possesses great computing power. Traditional machine learning system is a set of algorithms which initially breaks up the problem into several divisions, which are solved separately. After the process learns from those, it recombines the divisions to make the final decision (Halim et al., 2021; Rana et al., 2021; Rezaei et al., 2021; Sreenivasulu, \& Chatterjee, 2019). On the other hand, deep learning system simultaneously tackles the problem and accurately decides (Heavey \& Simsek, 2013; Jafari-Sadeghi et al., 2021; Schmidhuber, 2015).

Bennett and Parrado-Hernandez (2006) showed how operations research (OR) and machine learning (ML) are intertwined, and Hassan (2017) also showed that firms benefit from using advanced ML technology. Deep learning and OR are closely interrelated, as both use advanced analytics to solve complex problems through statistics, computer science, and mathematics (Kraus et al., 2020). Deep learning uses mathematical rules that could elaborate an event (Naoui et al., 2021). It can impact a firm's operational activities (Curtis \& Scheinberg, 2017; Garousi Mokhtarzadeh et al., 2020). Deep learning has been applied in several areas, including detecting fake news, self-driving cars, healthcare, visual recognition, and entertainment (Ghosh et al., 2021; Kar et al., 2019; Smith \& Lovgren, 2018). Deep learning technology has also been successfully used in predictive planning, manufacturing, supply chain management, scheduling, forecasting, capacity allocation, inventory optimization, and so on (Chatterjee et al., 2021; Murphy \& de Jongh, 2011; Nazir et al., 2020).

From the perspective of OR, use of deep learning has been considered a promising area to investigate, as it creates additional value to a firm's performance, sustainability, and productivity (Alkhaddar et al., 2012; Chatterjee et al., 2020b). Deep learning algorithms are considered an ensemble of ML algorithms, which are based on artificial neural networks comprised of multiple layers (Chatterjee, 2018; LeCun et al., 2015). Deep learning can be conceptualized as investigating existing cognitive structures and establishing various links to other concepts, realities, and ideas (Biggs, 1999; Entwistle, 1989). Deep learning models are concerned with areas such as time-setting data management, financial issues (Chatterjee et al., 2020a; Harmancioglu et al., 2010; Kumar et al., 2018; Nazir et al., 2020). In this context, predictive maintenance capability seems to play an important role in influencing firms to adopt smart manufacturing systems (Hassan, 2017). If a manufacturing unit adopts smart manufacturing systems that use deep learning technology (Cassia \& Magno, 2019; Guan et al., 2019), quality control tasks can also be ensured, as the systems can redevelop large assembly lines (Arfaoui et al., 2019; Marzouk \& Zaher, 2020). It is also easier to detect anomalies when a manufacturing unit uses deep learning technology (Belyaeva et al., 2020; 
Nguyen et al., 2020; Xiao et al., 2020), thus adopting this technology is perceived to be essential. From the review of literature, it has been observed that many studies have highlighted how deep learning could influence business activities. But these studies did not highlight the antecedents of deep learning capability that are helpful for adopting a smart manufacturing system in the context of the influence of technology turbulence as a moderator. Also, these studies did not highlight how adoption of a smart manufacturing system could impact the performance of firms being influenced by top management support as a moderator.

\section{Theoretical background and development of conceptual model}

\subsection{Theoretical background}

This study has attempted to identify the capabilities, or competencies, of a manufacturing firm that would adopt deep learning technology. To explain the insights in this context, we have referred to resource-based view (RBV) theory, which is also called resource-advantage theory (Barney, 1991). Resource has been defined as "a special type of resource specifically an organizationally embedded non-transferable firm-specific resource whose purpose is to improve the productivity of the other resources possessed by the firm" (Makadok, 2001, p.392). This theory highlights that a firm's resources are not all equally important, as they are not equally effective for adopting a specific technique (Fahy \& Smithee, 1999). In the context of this study, adoption of a smart manufacturing system is perceived to be dependent on a firm's specific qualities or capabilities such as predictive maintenance, quality control, as well as anomaly detection. These are valuable, rare, imperfectly imitable, and non-substitutable (VRIN) resources of a manufacturing firm, in the context of adopting deep learning technology. This is the core idea behind RBV theory. It highlights that, in adopting a new technology, a strategist will select the strategy that exploits the firm's internal capabilities rather than external opportunities (Hassan, 2017; Naoui et al., 2021). This theory posits that a firm's managers should identify the firm's key resources and evaluate which follow the VRIN criteria, and then protect as well as use such resources for adopting the targeted technology. In this study, a manufacturing firm's internal VRIN resources that are deemed to be components of deep learning technology capabilities are predictive maintenance capability, quality control capability, and anomaly detection capability.

A manufacturing firm deals with various types of data. Using data science, firms extract knowledge and create value from structured or unstructured datasets for the individuals. With the advent of deep learning technology, traditional data science has experienced a paradigm shift. The use of deep learning technology to nurture datasets to arrive at a smart business decision has become a dire necessity in the dynamic business situation. To keep pace with the dynamic environment, firms need to react and respond by transforming their traditional practices with deep learning technology for better performance. In this respect, support from top management is essential for developing among the firm's employees mutual trust, shared vision, and risk-taking abilities, which could facilitate the firm to adopt a smart system in the ever-changing scenario, which is in consonance with dynamic capability theory (Teece et al., 1997). Dynamic capability means "an ability to integrate, build, and reconfigure internal and external resources / competencies to address, and possibly shape rapidly changing business environments" (Teece, 2012; p. 1395). Dynamic capability is considered as a higher order capability, and it may be construed as an extension of RBV to explain the sustainability and competitive advantage of a firm in a highly volatile dynamic environment. 


\subsection{Formulation of hypotheses}

The literature review and the theories have guided us to identify the determinants that impact a firm's adoption of a smart manufacturing system, prompting firm performance. Here, we will discuss and explain the determinants and the moderating effects of technology turbulence and top management team support. We will formulate the hypotheses and develop a conceptual model.

\subsubsection{Predictive maintenance capability (PMC)}

Predictive maintenance techniques are designed to understand the conditions of a manufacturing firm's in-service equipment. These techniques help to determine when a specific equipment of the manufacturing unit need maintenance (Antomarioni et al., 2019). Predictive maintenance techniques help save costs over traditional routine, time-based maintenance. One of the main purposes of predictive maintenance is to allow corrective maintenance of the in-service equipment to be conveniently scheduled (Kaparthi \& Bumblauskas, 2020). This process helps to prevent the unexpected, abrupt failure of equipment used in the manufacturing firm (Tiddens et al., 2020; Wakiru et al., 2021). Predictive maintenance techniques support management by providing the right information about the lifecycle of in-service equipment, which protects the process from impediments (Halim et al., 2021; Navas et al., 2020). This technique also optimizes the use of spare parts in the manufacturing unit.

Deep learning technology helps the predictive maintenance process. Deep learning is used as a time-setting data management technique to ascertain the conditions and performances of the in-service equipment of the manufacturing unit (Naoui et al., 2021; Shahin et al., 2018; You, 2017). The technology collects useful data for giving timely support to the in-service equipment. The well-being of a particular equipment used in the manufacturing unit could be understood by deep learning technology, which eventually helps management to predict accurately when to take care of it. Thus, to effectively use PMC, deep learning technology is essential (Hassan, 2017; Naoui et al., 2021; Wakiru et al., 2021). The PMC, being one of the components of deep learning technology, is an intangible internal VRIN resource that helps a manufacturing firm to perform better, which is the core concept of RBV theory (Barney, 1991). All these inputs help to formulate the following hypothesis.

H1 Predictive maintenance capability (PMC) has a positive influence towards the adoption of a smart manufacturing system (SMS).

\subsubsection{Quality control capability (QCC)}

Quality control capability (QCC) is considered an essential component of a manufacturing unit (Cica et al., 2020; Eslamirad et al., 2020; Rana et al., 2020). Silbernagel et al. (2020) said that QCC is a process by which manufacturing firms can assess and review factors involved in a manufacturing firm's production quality. QCC is also considered a critical part of the quality management process that helps to fulfil all the necessary requirements for maintaining the quality of the products of a manufacturing unit (Wamba-Taguimdje et al., 2020).

Deep learning helps improve the quality control tasks of a manufacturing unit, as it helps to detect quality-related issues. Deep learning can optimize quality processes (Kannan \& Garad, 2021) and detect problems in quality with high levels of precision, which is difficult to achieve through traditional quality control mechanisms (Jamwal et al., 2021; Naoui et al., 
2021). One of the main impacts of deep learning technology is to improve the QCC of a manufacturing unit (Hassan, 2017). Thus, this capability is a critical internal resource in adopting a smart manufacturing system that eventually helps the manufacturing firms to achieve better performance (Halim et al., 2021). This concept is in consonance with the RBV theory (Barney, 1991), which posits that a firm is expected to use its VRIN resource to succeed, and QCC is construed as one such capability. Accordingly, it is hypothesized as follows.

H2 Quality control capability (QCC) positively influences the adoption of a smart manufacturing system (SMS).

\subsubsection{Anomaly detection capability (ADC)}

Anomaly detection capability (ADC) helps to identify the data points, observations, or events that deviate from the dataset's usual behavior (Jianhong \& Yanxiang, 2021; Lu et al., 2019). ADC helps in detecting vital incidents, such as include small technological glitches in the equipment used in the manufacturing unit or abnormal behavior of an in-service equipment, that might affect the output quality of the manufacturing unit (Ko et al., 2017; Salah Sobh, 2013).

Deep learning technology could help firms maintain the process and ascertain any anomaly in the datasets (Collins Jackson \& Lacey, 2020). Traditional processes for anomaly detection, like statistical analysis, are helpful, but deep learning technology can offer more precise information for manufacturing firms to use to correct their course (Liu et al., 2020; Xie et al., 2020). Thus, ADC can be considered an important component of deep learning technology and a strategic resource that the manufacturing firm can exploit to achieve success. This is the core idea of RBV theory (Barney, 1991). This capability is also construed to address rapidly changing business environments, which is in conformity with DCV theory (Teece et al., 1997). Accordingly, it is hypothesized as follows.

H3 Anomaly detection capability (ADC) positively influences the adoption of smart manufacturing systems (SMS).

\subsubsection{Adoption of a smart manufacturing system (SMS) and firm performance (FP)}

Manufacturing firms try to improve their performance by accurately analyzing different available datasets (Li et al., 2018; Pasi et al., 2020). This analysis comes under the purview of data science. Traditional data science has been experiencing a paradigm shift due to the advent of deep learning technology (Bag \& Pretorius, 2020; Jain \& Ajmera, 2020), which has gained popularity for surpassing traditional machine learning (Ghobakhloo, 2018; LeCun et al., 2015). Deep learning can handle all types of structured, semi-structured, or even unstructured data, including big data. This technique has been able to accurately solve problems with a single action, thus improving the performance of the manufacturing firm (Malaga \& Vinodh, 2021; Schmidhuber, 2015). Other researchers have also noted that the application of deep learning technology improves the overall performance of manufacturing firms (Curtis \& Scheinberg, 2017; Torres et al., 2020). These inputs suggest the following hypotheses:

H4 Adoption of smart manufacturing system (SMS) has a positive impact on the firm performance (FP). 


\subsubsection{Moderating effects of technology turbulence (TT)}

If the relationship between the two constructs is not fixed, a third variable can impact on the relationship by strengthening the relationship or by weaking the relationship. Even in some cases, the effects of the third variable can reverse the direction of the relationship between the two constructs. This third variable is known as moderating variable. Technology turbulence (TT) is one of the three environmental turbulences. The other two factors are market turbulence and competitive intensity (Shoham et al., 2005). TT is considered as a rate of change of process and product technologies, which are used for transforming inputs into outputs (Jaworski \& Kohli, 1993). Some researchers have opined that TT is the most critical component of environmental turbulence (Moorman \& Miner, 1997). In this context, Mason's opinion is very important, which said that environmental turbulence "is caused by changes in an interaction between various environmental factors especially, because of advances in technology and the confluence of computer, telecommunications, and media industries" (Mason, 2007, p.11). TT is considered to influence firms to implement strategy and even to formulate new strategies (Jeong et al., 2006). TT is also interpreted as the unpredictability of technology in the marketing environment (Song et al., 2005), which the firm needs to manage with its technology-driven knowledge resources. In the context of the present study, TT might impact the relationship between the adoption of deep learning technology by a manufacturing firm and its predictors. With this background, the following hypotheses are formulated.

H5a Technology turbulence (TT) has a moderating effect on the relationship between predictive maintenance capability (PMC) and the adoption of a smart manufacturing system (SMS).

H5b Technology turbulence (TT) has a moderating effect on the relationship between quality control capability (QCC) and the adoption of a smart manufacturing system (SMS).

H5c Technology turbulence (TT) has a moderating effect on the relationship between anomaly detection capability (ADC) and the adoption of smart manufacturing system (SMS).

\subsubsection{Moderating effects of top management team support (TS)}

Use of deep learning technology for improving firm performance is considered a new idea. However, when a firm introduces a new technology, it can experience some impediments, since the employees do not feel comfortable to use the new system, and they need appropriate training to use it (Chatterjee et al., 2019; Lin et al., 2020; Rafiki et al., 2019). In this context, active support from the top management team is essential (Thakur et al., 2016), to help align the employees with the firm's strategy to use deep learning technology (Mora Cortez \& Johnston, 2019; Youssef et al., 2018). TS is considered as the most critical success factor for adopting a new technology to improve firm performance (Young \& Jordan, 2008). Some researchers even opined that TS should be considered as the principal ingredient for a "project success recipe" (Zwikael, 2008). In this context, it is perceived that TS influences the relationship between adopting a new technology and the consequences. Hence it is hypothesized as follows.

H6 Top management team support (TS) acts as a moderating variable to impact the relationship between the adoption of a smart manufacturing system (SMS) and firm performance (FP). 


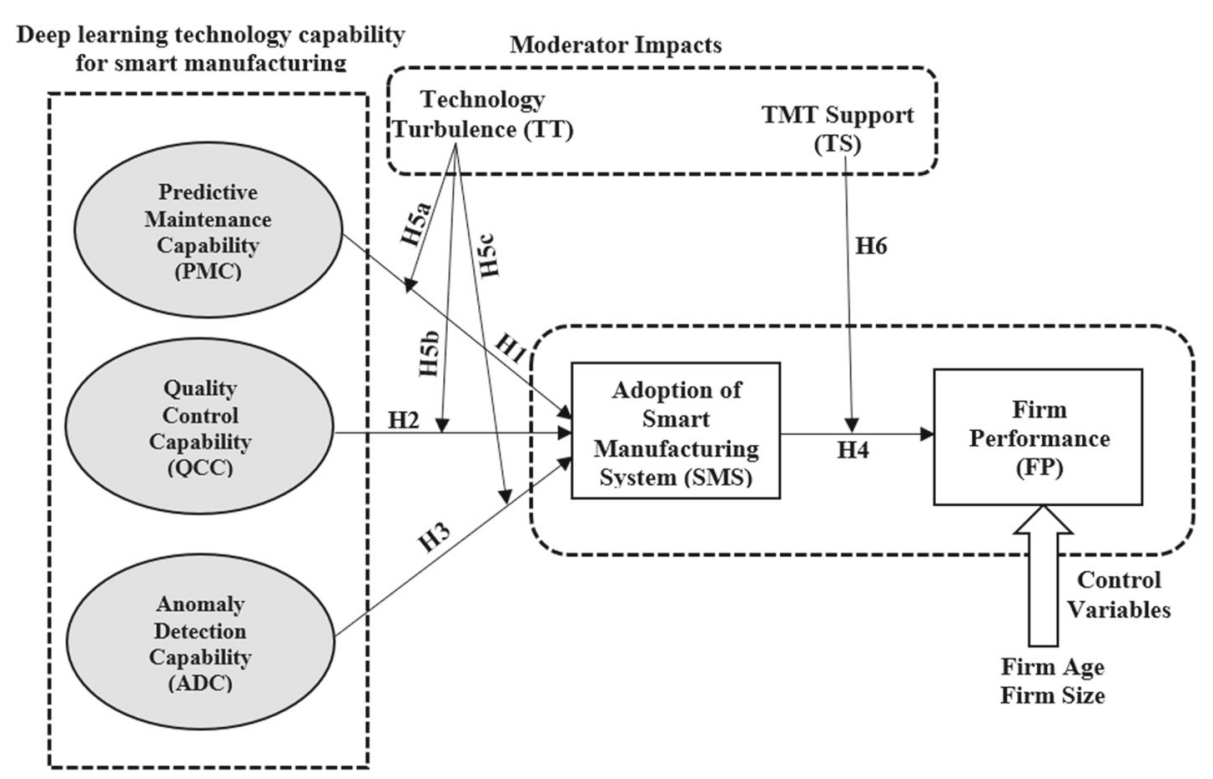

Fig. 1 Conceptual model

Previous studies have suggested that there are essential features of a manufacturing firm that might influence some of the critical constructs related to adopting a new technology (Porter \& Donthu, 2006). For ensuring better delineation of the relationship between the determinants of the model, two control variables, characterizing firm performance, have duly been considered to confirm rigorous synthesis between the theoretical connections of the model. The control variables are firm age and firm size. With all these inputs, the following model is developed conceptually, as shown in Fig. 1.

\section{Research methodology}

For hypotheses testing and for validating the conceptual model, the partial least squares (PLS) structural equation modelling (SEM) technique has been used, as it can accurately analyze the cause-effect relationship between variables (Hair et al., 2018; Schuberth et al., 2018). This technique has been followed because it helps to analyze a complex model in a simpler way and yields better result to explain an exploratory study like this (Wamba et al., 2020). This technique does not impose any sample restriction (Sarstedt et al., 2014). Also, with this technique, any data can be analyzed because it does not impose any restriction on data that are not normally distributed, which is not true in covariance-based SEM (Kock, 2019). This technique involves quantifying the usable responses from participants of a survey. The quantification has been done in this study using a five-point Likert scale.

\subsection{Measurement instruments}

Studies of extant literature and the concept of the constructs helped to prepare the research items to assess the content validity of the constructs. Modification of the items was done 
through a series of correctional processes. However, at the outset, 35 items were prepared. Five experts, having expertise in the domain of this study, were consulted for their opinions to improve the comprehensiveness and clarity of the research items. These 35 items were prepared in the form of statements, which were then pretested to modify the wordings of the items. The items were prepared in such a way to help to understand the respondents' attitude about deep learning technology. Eventually, the 35 items were fine-tuned.

\subsection{Collection of data}

Purposeful sampling was preferred for data collection. Manufacturing firms of different sizes and ages were targeted. We obtained the list of manufacturing firms from the database of the Bombay Chamber of Commerce and Industry, India. Emails and telephone calls were chosen as the media used to contact the professionals of these firms who were reported to be knowledgeable about technology adoption and operation management. At the outset, we contacted 757 manufacturing firms at random. Through emails and telephone calls, we ascertained that out of these 757 manufacturing firms, 491 manufacturing firms were interested in adopting smart technology for their units. From these 491 manufacturing firms, it was possible to gather contact information of 942 respondents. We sent those 942 respondents emails with the response sheet containing 35 items for their feedback. On the response sheet, they were informed that their anonymity and confidentiality would be strictly preserved. They were given two months (January and February 2021) to respond. During this time, we obtained 487 responses, which is a response rate of $51.7 \%$. For conducting the non-response bias test, recommendations provided by Armstrong and Overton (1977) have been followed. Chi square tests and independent t-tests have been conducted by consideration of the feedback from the first and the last 100 responses. No appreciable deviation in the two results was noted. It confirms that the results do not involve non-response bias. We scrutinized the responses and found that, out of 487 responses, 14 responses were incomplete. The responses were considered incomplete because either some respondents put tick marks in more than one option against some of the questions or some returned response sheets that were completely vacant. We did not consider these 14 incomplete responses, and therefore, we analyzed the responses of 473 respondents against 35 items. Details of the respondents are shown in the Table 1.

Table 1 Details of respondents $(\mathrm{N}=473)$

\begin{tabular}{llll}
\hline Category & Particulars & No. of respondents & Percentage (\%) \\
\hline Small & $<400$ employees & 104 & 21.9 \\
Medium & 400 to 900 employees & 196 & 41.4 \\
Large & $>900$ employees & 173 & 36.7 \\
Age & $<5$ years & 83 & 17.5 \\
& 5 to 10 years & 183 & 38.7 \\
& $>10$ years & 207 & 43.8 \\
\hline
\end{tabular}




\section{Analysis of data and results}

\subsection{Measurement model}

To assess the content validity of each item, the loading factor (LF) of each has been estimated. To examine the validity, reliability, consistency, and multicollinearity defects of each construct, we estimated the average variance extracted (AVE), composite reliability (CR), Cronbach's alpha $(\alpha)$, and variance inflation factor (VIF) of each construct. All the estimated values are found to be within the allowable range. The results are shown in Table 2.

It has been observed that the square roots of all the AVEs are greater than the corresponding bifactor correlation coefficients, satisfying Fornell and Larcker criterion (Fornell \& Larcker, 1981). It confirms discriminant validity. Results are shown in Table 3.

To supplement the Fornell and Larcker test (Fornell \& Larcker, 1981), HeterotraitMonotrait (HTMT) test has been duly performed. The correlation ratio test has been conducted to reverify the discriminant validity in this study (Henseler et al., 2014). On analysis of the results, it has been observed that all the estimated values of the relevant constructs are less than the highest threshold value of 0.85 (Voorhees et al., 2016). It also confirms the Fornell and Larcker criteria. The results are shown in Table 4.

\subsection{Moderation analysis (multigroup analysis, MGA)}

To examine the effects of the two moderators, technology turbulence (TT) and top management team support (TS), we performed multigroup analysis (MGA). For this, the bootstrapping procedure was conducted with consideration of 5000 resamples. The effects of the moderator TT was divided into two categories, high TT and low TT, whereas the moderator TS was divided into strong TS and weak TS categories. The moderator TT acts on the linkages $\mathrm{H} 1, \mathrm{H} 2$, and $\mathrm{H} 3$, whereas TS acts on the relationship covering $\mathrm{H} 4$. If the p-value difference of a moderator is found to be either less than 0.05 or greater than 0.95 , then the effects of that moderator on that linkage are significant (Hair et al., 2016). The MGA highlights that the effects of these two moderators, TT and TS, on their respective linages are significant. The results are shown in Table 5.

\subsection{Common method variance (CMV)}

In the context of survey-based data, there is possibility of CMV because of results emerging from multifarious sources including implicit social desirability in connection with answering questions in a specific way. It affects the indicators for showing certain amount of variance (Podsakoff et al., 2003, 2012). Procedural remedies have duly been followed to minimize the effects of CMV as preemptive measures (Jajja et al., 2018). The format and the recitals of the questions in the pretest stage during survey have been corrected for enhancement of their readability and simplicity. Also, at the survey stage, the prospective respondents were assured that their anonymity and confidentiality will be strictly preserved. These procedural measures were taken to mitigate the possibility of biased replies as far as possible. Nevertheless, statistical analysis was done to estimate the severity of CMV. Harman's Single Factor Test (SFT) was performed (Hossain et al., 2020). The first factor emerged as $26.92 \%$ which is less than the recommended highest threshold value of 50\% (Podsakoff et al., 2003). Since it has been opined by the scholars that for CMV, the Harman's SFT is not so robust (Ketokivi \& Schroeder, 2004) and for this, to reconfirm the Harman's SFT, marker variable correlation 
Table 2 Measurement properties

\begin{tabular}{|c|c|c|c|c|c|c|c|}
\hline Constructs/items & $\mathrm{LF}$ & $\mathrm{CR}$ & AVE & A & VIF & t-values & No. of items \\
\hline PMC & & 0.89 & 0.86 & 0.93 & 4.2 & & 7 \\
\hline PMC1 & 0.93 & & & & & 22.88 & \\
\hline PMC2 & 0.96 & & & & & 23.11 & \\
\hline PMC3 & 0.95 & & & & & 27.16 & \\
\hline PMC4 & 0.94 & & & & & 24.18 & \\
\hline PMC5 & 0.90 & & & & & 31.12 & \\
\hline PMC6 & 0.92 & & & & & 32.17 & \\
\hline PMC7 & 0.89 & & & & & 33.13 & \\
\hline QCC & & 0.88 & 0.86 & 0.92 & 4.1 & & 7 \\
\hline QCC1 & 0.88 & & & & & 24.24 & \\
\hline QCC2 & 0.90 & & & & & 28.17 & \\
\hline QCC3 & 0.95 & & & & & 29.88 & \\
\hline QCC4 & 0.95 & & & & & 32.83 & \\
\hline QCC5 & 0.94 & & & & & 23.27 & \\
\hline QCC6 & 0.92 & & & & & 25.11 & \\
\hline QCC7 & 0.96 & & & & & 19.29 & \\
\hline $\mathrm{ADC}$ & & 0.90 & 0.87 & 0.94 & 3.9 & & 7 \\
\hline $\mathrm{ADC} 1$ & 0.97 & & & & & 27.17 & \\
\hline $\mathrm{ADC} 2$ & 0.94 & & & & & 26.01 & \\
\hline $\mathrm{ADC} 3$ & 0.93 & & & & & 26.28 & \\
\hline $\mathrm{ADC} 4$ & 0.88 & & & & & 29.37 & \\
\hline ADC5 & 0.89 & & & & & 21.11 & \\
\hline ADC6 & 0.97 & & & & & 24.01 & \\
\hline $\mathrm{ADC7}$ & 0.96 & & & & & 25.74 & \\
\hline SMS & & 0.91 & 0.88 & 0.95 & 3.7 & & 7 \\
\hline SMS1 & 0.94 & & & & & 26.11 & \\
\hline SMS2 & 0.96 & & & & & 29.22 & \\
\hline SMS3 & 0.93 & & & & & 23.06 & \\
\hline SMS4 & 0.97 & & & & & 28.72 & \\
\hline SMS5 & 0.89 & & & & & 31.41 & \\
\hline SMS6 & 0.90 & & & & & 33.12 & \\
\hline SMS7 & 0.95 & & & & & 37.32 & \\
\hline FP & & 0.92 & 0.87 & 0.97 & 4.6 & & 7 \\
\hline FP1 & 0.90 & & & & & 24.28 & \\
\hline FP2 & 0.95 & & & & & 26.11 & \\
\hline FP3 & 0.90 & & & & & 24.23 & \\
\hline FP4 & 0.96 & & & & & 29.17 & \\
\hline FP5 & 0.97 & & & & & 19.28 & \\
\hline FP6 & 0.92 & & & & & 28.29 & \\
\hline FP7 & 0.94 & & & & & 24.47 & \\
\hline
\end{tabular}


Table 3 Discriminant validity test (Fornell and Larcker criterion)

\begin{tabular}{|c|c|c|c|c|c|c|}
\hline Construct & PMC & QCC & $\mathrm{ADC}$ & SMS & FP & AVE \\
\hline PMC & 0.92 & & & & & 0.86 \\
\hline QCC & $0.17 *$ & 0.92 & & & & 0.86 \\
\hline $\mathrm{ADC}$ & 0.19 & 0.25 & 0.93 & & & 0.87 \\
\hline SMS & 0.22 & $0.19 * *$ & 0.17 & 0.94 & & 0.88 \\
\hline FP & $0.24 * * *$ & 0.17 & $0.21 *$ & $0.26 * *$ & 0.93 & 0.87 \\
\hline
\end{tabular}

$* \mathrm{p}<0.05 ; * * \mathrm{p}<0.01 ; * * * \mathrm{p}<0.001$

Table 4 Heterotrait-monotrait (HTMT) test

\begin{tabular}{llllll}
\hline Construct & PMC & QCC & ADC & SMS & FP \\
\hline PMC & & & & & \\
QCC & 0.22 & & & \\
ADC & 0.19 & 0.25 & & \\
SMS & 0.23 & 0.19 & 0.17 & \\
FP & 0.46 & 0.32 & 0.26 & 0.24 & \\
\hline
\end{tabular}

Table 5 Moderator analysis (MGA)

\begin{tabular}{|c|c|c|c|c|}
\hline Linkages & Hypotheses & Moderators & $\mathrm{p}$-value differences & Remarks \\
\hline$(\mathrm{PMC} \rightarrow \mathrm{SMS}) \times \mathrm{TT}$ & H5a & $\begin{array}{l}\text { Technology } \\
\text { turbulence (TT) }\end{array}$ & 0.02 & Significant \\
\hline$(\mathrm{QCC} \rightarrow \mathrm{SMS}) \times \mathrm{TT}$ & H5b & $\begin{array}{l}\text { Technology } \\
\text { turbulence (TT) }\end{array}$ & 0.04 & Significant \\
\hline$(\mathrm{ADC} \rightarrow \mathrm{SMS}) \times \mathrm{TT}$ & H5c & $\begin{array}{l}\text { Technology } \\
\text { turbulence (TT) }\end{array}$ & 0.01 & Significant \\
\hline$(\mathrm{SMS} \rightarrow \mathrm{FP}) \times \mathrm{TS}$ & H6 & TMT support (TS) & 0.02 & Significant \\
\hline
\end{tabular}

test (Lindell \& Whitney, 2001) has been conducted. The results indicated that the difference between the original correlations as well as CMV-adjusted correlations were very small ( $\leq$ 0.06) (Mishra et al., 2018) for all the relevant constructs. From these results, it can be safely concluded that CMV could not severely distort the results and the prediction of this present study.

\subsection{Hypotheses testing (SEM)}

To test the hypotheses, the bootstrapping procedure with consideration of 5000 resamples has been followed using SmartPLS (Henseler et al., 2009a, 2009b; Mishra et al., 2018). By considering omission distance 7, cross-validated redundancy has been estimated for the 
dependent variables. The $\mathrm{Q}^{2}$ value came out to be 0.062 (positive). This confirms that the model has due predictive relevance.

To ascertain if the model is fit, the Standardized Root Mean Square Residual Error (SRMR) has been taken to be a standard index, and its values have been estimated, which are found to be 0.062 for PLS and 0.035 for PLSc, both being less than the highest threshold value of 0.08 (Hu \& Bentler, 1999). This confirms that the model is in order. This process has helped to compute path coefficients, $\mathrm{p}$-values, and $\mathrm{R}^{2}$ values. The detailed results are provided in Table 6 .

The validated model is shown in Fig. 2.

Table 6 Estimation of path coefficients, p-values, and $\mathrm{R}^{2}$ values

\begin{tabular}{lllll}
\hline Linkages & Hypotheses & Path coefficients $/ \mathrm{R}^{2}$ values & $\mathrm{p}$-values & Remarks \\
\hline Effects on SMS & & $\mathrm{R}^{2}=0.31$ & & \\
By PMC & H1 & 0.31 & $\mathrm{p}<0.05(*)$ & Supported \\
By QCC & H2 & 0.19 & $\mathrm{p}<0.01(* *)$ & Supported \\
By ADC & H3 & 0.23 & $\mathrm{p}<0.05(*)$ & Supported \\
Effects on FP & & $\mathrm{R}^{2}=0.66$ & & Supported \\
By SMS & H4 & 0.37 & $\mathrm{p}<0.001(* * *)$ & Supported \\
$(\mathrm{PMC} \rightarrow$ SMS $) \times$ TT & H5a & 0.16 & $\mathrm{p}<0.05(*)$ & Supported \\
$(\mathrm{QCC} \rightarrow$ SMS $) \times$ TT & H5b & 0.22 & $\mathrm{p}<0.01(* *)$ & Supported \\
$(\mathrm{ADC} \rightarrow$ SMS $) \times$ TT & H5c & 0.19 & $\mathrm{p}<0.001(* * *)$ & Supported \\
$(\mathrm{SMS} \rightarrow$ FP $) \times$ TS & H6 & 0.28 &
\end{tabular}

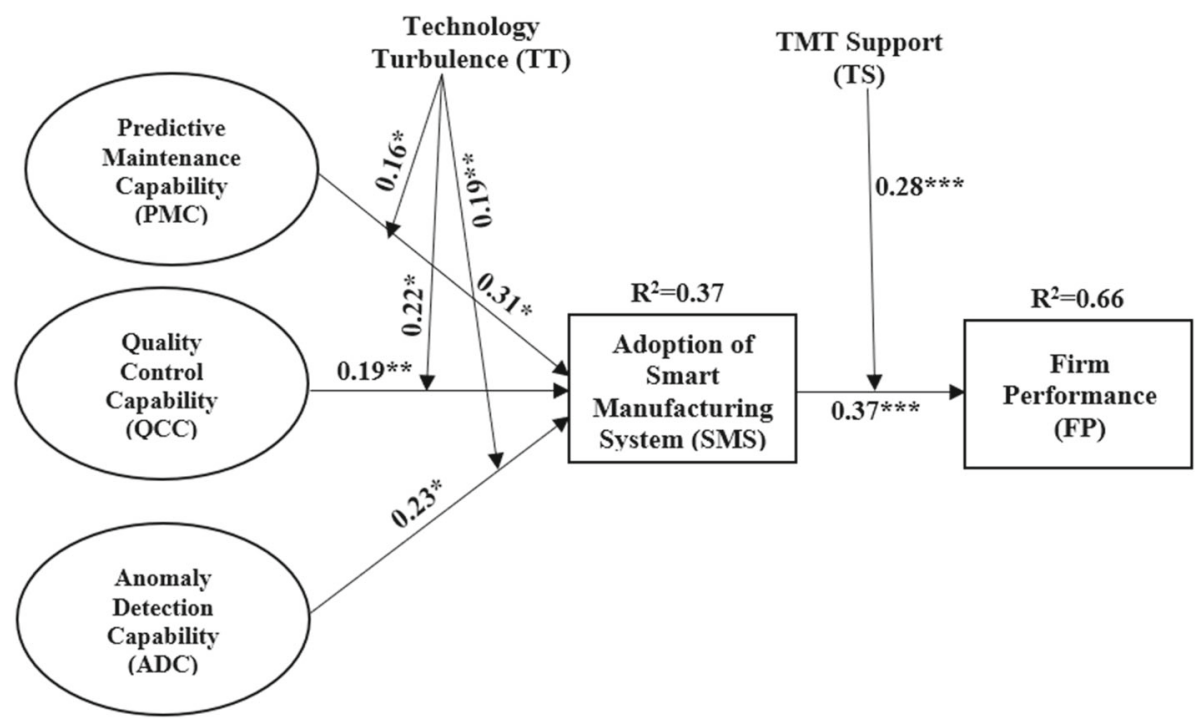

Fig. 2 Validated model (SEM) 


\subsection{Results}

In this study, eight hypotheses were formulated, out of which, four hypotheses are concerned with the moderating effects of TT on the relationships of $\mathrm{H} 1, \mathrm{H} 2$, and $\mathrm{H} 3$. The moderator TS impacted on the relationship covered by H4. From the PLS-SEM analysis, it appears that all the hypotheses have been supported. The impacts of PMC, QCC, and ADC on SMS $(\mathrm{H} 1, \mathrm{H} 2$, and H3) are all significant, since the concerned path coefficients are $0.31,0.19$, and 0.23 , respectively, with corresponding levels of significance as $\mathrm{p}<0.05\left(^{*}\right), \mathrm{p}<0.01(* *)$, and $\mathrm{p}<0.05(*)$. The effects of SMS on FP are also significant $(\mathrm{H} 4)$, as the concerned path coefficient is 0.37 with level of significance as $\mathrm{p}<0.001(* * *)$. The moderating effects of TT on $\mathrm{H} 1, \mathrm{H} 2$, and $\mathrm{H} 3$ are all significant, since the concerned path coefficients are $0.16,0.22$, and 0.19 , respectively, with the relevant levels of significance as $\mathrm{p}<0.05\left(^{*}\right), \mathrm{p}<0.05\left(^{*}\right)$, and $\mathrm{p}<0.01(* *)$. The moderating effects of TS on H4 are also significant, since the concerned path coefficient is 0.28 with level of significance $\mathrm{p}<0.001(* * *)$. Regarding the $\mathrm{R}^{2}$ values (coefficient of determinant), the results show that PMC, QCC, and ADC could explain SMS to the tune of $37 \%$, whereas SMS could explain FP to the extent of $66 \%$, which is the predictive power of the model.

\section{Discussion on results}

This study investigated the deep learning capability for smart manufacturing, and it has shown that deep learning capability comprises predictive maintenance capability (PMC), quality control capability (QCC), and anomaly detection capability (ADC). The study has also shown that these three exogenous variables, PMC, QCC, and ADC, could impact SMS, which in turn triggers firm performance (FP). This study has shown that these three capabilities, being the principal components of deep learning capability, could facilitate a manufacturing firm to adopt a smart manufacturing system, which could improve its performance. The study has also shown that the moderator TT has significant impacts on the linkages covered by $\mathrm{H} 1, \mathrm{H} 2$, and H3. Also, the study has shown that the moderating effects of TS on the linkage H4 are also significant, as MGA showed. The effects of these two moderators have duly strengthened the proposed theoretical model, as it could ultimately achieve a high explanative power of $66 \%$.

Now we will discuss the effects of the moderator TT on $\mathrm{H} 1, \mathrm{H} 2$, and $\mathrm{H} 3$ with graphical analysis. The effects of high TT and low TT on H1, H2, and $\mathrm{H} 3$ are shown in three graphs in Fig. 3.

The three graphs show that, with an increase of PMC (for H1), QCC (for H2), and ADC (for H3), the rates of increase of SMS are more from the effects of low TT compared to the effects of high TT, since the gradients of the dotted lines (low TT) are more than the gradients of the continuous lines (high TT). The gradient of a straight line is considered as a trigonometrical tangent of the angle, which the straight line makes with the positive direction of the horizontal axis.

Figure 4 represents the moderating effects of TS on H4, and it appears that, as SMS increases, the rate of increase of FP is more for the effects of strong TS compared to the effects of weak TS, since the gradient of the continuous line (strong TS) is more than the gradient of the dotted line (weak TS). 


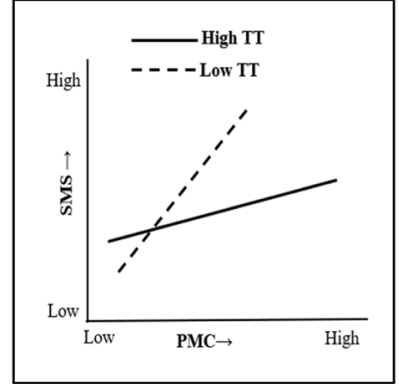

Effects of TT on $\mathrm{H} 1$

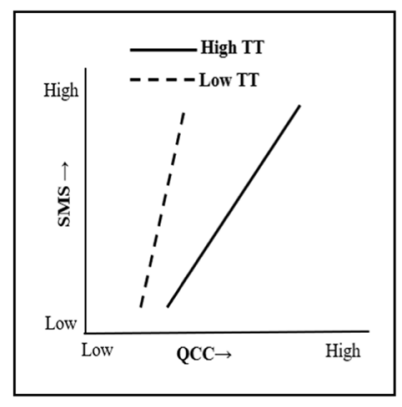

Effects of TT on H2

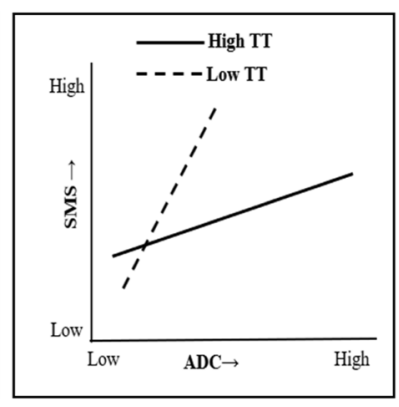

Effects of TT on $\mathrm{H} 3$

Fig. 3 Effects of TT on H1, H2, and H3

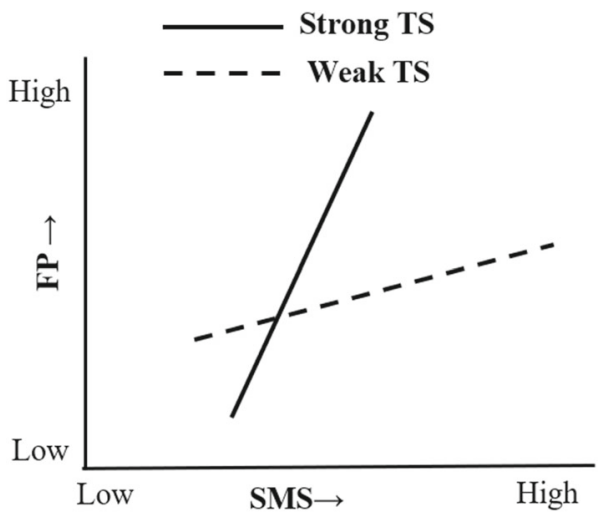

Fig. 4 Effects of TS on $\mathrm{H} 4$

\subsection{Theoretical contributions}

This study has investigated the effects of the components of deep learning capability on manufacturing firms' adoption of smart manufacturing systems. This study has shown that predictive maintenance capability (PMC), quality control capability (QCC), and anomaly detection capability (ADC) could impact a manufacturing firm to adopt a smart manufacturing system. This study has also shown that adoption of a smart manufacturing system could impact firm performance.

No extant literature has shown how the different components of deep learning capability could impact a firm to adopt a smart manufacturing system, which ultimately could improve the firm performance. This attempt is unique, and is claimed to have added value to the extent literature. No other studies have nurtured how technology turbulence could influence the relationship between the adoption of smart manufacturing system with its three predictors. Our study is a novel attempt, and as such, we claim it has added value to the extent literature. Moreover, investigating the moderating effects of TS on the relation SMS $\rightarrow$ FP (H4) is also a novel addition to the literature. We claim it to be a special theoretical contribution of this study. 
This study deals with the adoption of smart manufacturing systems by firms. Hence, principally this study focuses on the adoption of technology. To explain this, a standard adoption model could have been used, but this was not done. Instead, this study used some better suited variables and proposed a successful theoretical model with a high explanative power $(66 \%)$. This is also claimed to be a unique theoretical contribution of this study. Our study has successfully used resource-based view (RBV) theory (Barney, 1991) and dynamic capability view (DCV) theory (Teece et al., 1997). The concepts of these two theories have been appropriately extended to interpret this study successfully. The details of how the theories were applied have been elucidated in Sect. 3. The appropriate use of these two theories to interpret the proposed theoretical model is also claimed as a special theoretical contribution of our study. In a study of Naoui et al. (2020), a deep learning algorithm was used for analyzing big data in smart cities. That study provided effective inputs for our study, and we successfully showed the contributions that deep learning capability has in the adoption of smart manufacturing systems in the firms we studied. This contributes additional value to the extant literature, and it is another theoretical contribution of our study.

\subsection{Practical implications}

From this study, we have seen that predictive maintenance capability (PMC), quality control capability (QCC), and anomaly detection capability (ADC) are the three important components of deep learning technology capability. These are also predictors of firms using smart manufacturing systems ( $\mathrm{H} 1, \mathrm{H} 2$, and H3). This study has also shown that top management team support (TS) acts as an effective moderator to influence the relationship between adoption of smart manufacturing system (SMS) and firm performance (FP) (H6). This implies that manufacturing firms' leadership teams should actively support the adoption of deep learning technology for the manufacturing units.

Our study has shown that technology turbulence impacts adoption of smart manufacturing systems (H5a, H5b, and H5c). This implies that maintenance teams, quality control teams, and other related teams who oversee the equipment and instruments in the manufacturing units need to be trained properly. This will help these teams to handle any technological issues that might crop up while adopting deep learning technology. Training will improve the expertise of the members of these teams, and they can then work as trainers as well as experts in their respective manufacturing plants.

It has already been stated that top management teams should actively support the adoption of smart manufacturing systems integrated with deep learning technology so that firms' overall performance is enhanced (H4). The performance of the firms could be improved provided the top management motivates and encourages the mangers, entry level staff, and other employees to adopt smart manufacturing system.

\subsection{Limitations and future scope}

This study is based on the inputs from the employees of manufacturing firms in India, hence this study provides the findings which are India-specific. It lacks from generalizability. To generalize the findings, future researchers may conduct extensive surveys by obtaining inputs from the employees of different manufacturing firms across the globe. The study is based on cross-sectional data. Future researchers may address this issue by conducting a longitudinal survey. Future researchers may also consider the inputs from different types of firms, which our study did not include. The explanative power of the model is $66 \%$. Consideration of other 
boundary conditions could have improved the strength of the model, which is left for future researchers to nurture. The survey arrived at the results by considering inputs from 473 usable respondents. This size of a sample cannot represent the entire manufacturing industry, and future researchers might conduct the survey on a larger sample.

\section{References}

Adebowale, M. A., Lwin, K. T., \& Hossain, M. A. (2020). Intelligent phishing detection scheme using deep learning algorithms. Journal of Enterprise Information Management. https://doi.org/10.1108/JEIM-012020-0036

Alkhaddar, R., Wooder, T., Sertyesilisik, B., \& Tunstall, A. (2012). Deep learning approach's effectiveness on sustainability improvement in the UK construction industry. Management of Environmental Quality, 23(2), 126-139.

Antomarioni, S., Bevilacqua, M., Potena, D., \& Diamantini, C. (2019). Defining a data-driven maintenance policy: An application to an oil refinery plant. International Journal of Quality \&amp; Reliability Management, 36(1), 77-97.

Arfaoui, N., Hofaidhllaoui, M., \& Chawla, G. (2019). Social performance of the company: An explanation centralized on the social and technological factors. EuroMed Journal of Business, 15(1), 102-126.

Armstrong, J. S., \& Overton, T. S. (1977). Estimating nonresponse bias in mail surveys. Journal of Marketing Research, 14(3), 396-402.

Aruna Santhi, J., \& Vijaya Saradhi, G. (2021). Attack detection in medical Internet of things using optimized deep learning: Enhanced security in healthcare sector. Data Technologies and Applications. https://doi. org/10.1108/DTA-10-2020-0239

Bag, S., \& Pretorius, J. H. C. (2020). Relationships between Industry 4.0, sustainable manufacturing and circular economy: Proposal of a research framework. International Journal of Organizational Analysis. https://doi.org/10.1108/IJOA-04-2020-2120

Barney, J. B. (1991). Firm resources and sustained competitive advantage. Journal of Management, 17(1), 99-120.

Belyaeva, Z., Shams, S. M. R., Santoro, G., \& Grandhi, B. (2020). Unpacking stakeholder relationship management in the public and private sectors: The comparative insights. EuroMed Journal of Business, 15(3), 269-281.

Bennett, K., \& Parrado-Hernandez, E. (2006). The interplay of optimization and machine learning research. Journal of Machine Learning Research, 7, 1265-1281.

Biggs, J. B. (1999). Teaching for quality learning at university. Open University Press.

Bromuri, S., Henkel, A. P., Iren, D., \& Urovi, V. (2020). Using AI to predict service agent stress from emotion patterns in service interactions. Journal of Service Management. https://doi.org/10.1108/JOSM-06-20190163

Cassia, F., \& Magno, F. (2019). A framework to manage business-to-business branding strategies. EuroMed Journal of Business, 14(2), 110-122.

Chatterjee, S. (2018). Internet of things and social platforms: An empirical analysis from Indian consumer behavioral perspective. Journal of Behavior \&amp; Information Technology, 39(2), 133-149.

Chatterjee, S., Chaudhuri, R., \& Vrontis, D. (2020). Does data-driven culture impact innovation and performance of a firm? An empirical examination. Annals of Operational Research. https://doi.org/10.1007/ s10479-020-03887-z

Chatterjee, S., Chaudhuri, R., Vrontis, D., Thrassou, A., \& Ghosh, S. K. (2020b). ICT-enabled CRM system adoption: A dual Indian qualitative case study and conceptual framework development. Journal of Asia Business Studies, 15(2), 257-277.

Chatterjee, S., Ghosh, S. K., \& Chaudhuri, R. (2019). Adoption of ubiquitous customer relationship management (uCRM) in enterprise: Leadership support and technological competence as moderators. Journal of Relationship Marketing, 19(2), 75-92.

Chatterjee, S., Ghosh, S. K., Chaudhuri, R., \& Chaudhuri, S. (2021). Adoption of AI-integrated CRM system by Indian industry: From security and privacy perspective. Information and Computer Security, 29(1), $1-24$.

Chen, J., Lim, C. P., Tan, K. H., Govindan, K., \& Kumar, A. (2021). Artificial intelligence-based humancentric decision support framework: An application to predictive maintenance in asset management under pandemic environments. Annals of Operations Research. https://doi.org/10.1007/s10479-021-04373-w 
Cica, D., Sredanovic, B., Tesic, S., \& Kramar, D. (2020). Predictive modeling of turning operations under different cooling/lubricating conditions for sustainable manufacturing with machine learning techniques. Applied Computing and Informatics. https://doi.org/10.1016/j.aci.2020.02.001

Collins Jackson, A., \& Lacey, S. (2020). The discrete Fourier transformation for seasonality and anomaly detection of an application to rare data. Data Technologies and Applications, 54(2), 121-132.

Curtis, F. E., \& Scheinberg, K. (2017). Optimization methods for supervised machine learning: from linear models to deep learning. In leading developments from INFORMS communities. Tutorial in Operations Research. https://doi.org/10.1287/educ.2017.0168

Entwistle, N. (1989). Approaches to studying and course perceptions: The case of the disappearing relationship. Studies in Higher Education, 4, 155-156.

Eslamirad, N., Malekpour Kolbadinejad, S., Mahdavinejad, M., \& Mehranrad, M. (2020). Thermal comfort prediction by applying supervised machine learning in green sidewalks of Tehran. Smart and Sustainable Built Environment, 9(4), 361-374.

Fahy, J., \& Smithee, A. (1999). Strategic marketing and the resource based view of the firm. Journal of the Academy of Marketing Science Review, 10, 1-21.

Fornell, C., \& Larcker, D. F. (1981). Evaluating structural equation models with unobservable variables and measurement error. Journal of Marketing Research, 18(1), 39-50.

Garousi Mokhtarzadeh, N., Amoozad Mahdiraji, H., Jafari-Sadeghi, V., Soltani, A., \& Abbasi Kamardi, A. (2020). A product-technology portfolio alignment approach for food industry: A multi-criteria decision making with z-numbers. British Food Journal, 122(12), 3947-3967.

Ghobakhloo, M. (2018). The future of manufacturing industry: a strategic roadmap toward Industry 4.0. Journal of Manufacturing Technology Management, 29(6), 910-936.

Ghosh, S. K., Chaudhuri, R., \& Chaudhuri, S. (2021). Adoption of AI-integrated CRM system by Indian industry: From security and privacy perspective. Information and Computer Security, 29(1), 1-24.

Grand View Research. (2017). Deep learning market size, share \& trends analysis report. Retrieved May 9, 2021, from https://www.grandviewresearch.com/industry-analysis/deep-learning-market

Guan, C., Qin, S., \& Long, Y. (2019). Apparel-based deep learning system design for apparel style recommendation. International Journal of Clothing Science and Technology, 31(3), 376-389.

Hair, J. F., Jr., Hult, G. T. M., Ringle, C., \& Sarstedt, M. (2016). A primer on partial least squares structural equation modeling (PLS-SEM) (2nd ed.). Sage.

Hair, J. F., Sarstedt, M., Ringle, C. M., \& Gudergan, S. P. (2018). Advanced issues in partial least squares structural equation modeling (PLS-SEM). Sage.

Halim, Z., Shuhidan, S. M., \& Sanusi, Z. M. (2021). Corporation financial distress prediction with deep learning: Analysis of public listed companies in Malaysia. Business Process Management Journal. https:// doi.org/10.1108/BPMJ-06-2020-0273

Harmancioglu, N., Grinstein, A., \& Goldman, A. (2010). Innovation and performance outcomes of market information collection efforts: The role of top management team involvement. International Journal of Research in Marketing, 27(1), 33-43.

Hassan, Y. F. (2017). Deep learning architecture using rough sets and rough neural networks. Kybernetes, 46(4), 693-705.

Heavey, C., \& Simsek, Z. (2013). Top management compositional effects on corporate entrepreneurship: The moderating role of perceived technological uncertainty. Journal of Product Innovation Management, 30(5), 837-855.

Henseler, J., Dijkstra, T. K., Sarstedt, M., Ringle, C. M., Diamantopoulos, A., Straub, D. W., \& Calantone, R. J. (2014). Common beliefs and reality about PLS: Comments on Rönkkö and Evermann. Organizational Research Methods, 17(2), 182-209.

Henseler, J., Ringle, C. M., \& Sinkovics, R. R. (2009a). The use of partial least squares path modeling in international marketing. Advances in International Marketing, 20(1), 277-319.

Henseler, J., Ringle, C. M., \& Sinkovics, R. R. (2009b). The use of partial least squares path modeling in international marketing. New Challenges to International Marketing, Advances in International Marketing, 20, 277-319.

Hossain, T. M. T., Akter, S., Kattiyapornpong, U., \& Dwivedi, Y. (2020). Reconceptualizing integration quality dynamics for omnichannel marketing. Industrial Marketing Management, 87, 225-241.

Hu, L. T., \& Bentler, P. M. (1999). Cutoff criteria for fit indexes in covariance structure analysis: Conventional criteria versus new alternatives. Structural Equation Modeling: A Multidisciplinary Journal, 6(1), 1-55.

Jafari-Sadeghi, V., Garcia-Perez, A., Candelo, E., \& Couturier, J. (2021). Exploring the impact of digital transformation on value creation through technology entrepreneurship: Role of technology readiness, exploration and exploitation. Journal of Business Research, 124, 100-111. 
Jain, V., \& Ajmera, P. (2020). Modelling the enablers of Industry in the Indian manufacturing industry 4.0. International Journal of Productivity and Performance Management. https://doi.org/10.1108/IJPPM-072019-0317

Jajja, M. S. S., Chatha, K. A., \& Farooq, S. (2018). Impact of supply chain risk on agility performance: Mediating role of supply chain integration. International Journal of Production Economics, 205, 118-138.

Jamwal, A., Agrawal, R., Sharma, M., Kumar, A., Kumar, V., \& Garza-Reyes, J. A. A. (2021). Machine learning applications for sustainable manufacturing: A bibliometric-based review for future research. Journal of Enterprise Information Management. https://doi.org/10.1108/JEIM-09-2020-0361

Jaworski, B. J., \& Kohli, A. K. (1993). Market orientation: antecedents and consequences. Journal of Marketing, 57(3), 53-70.

Jeong, I., Pae, J. H., \& Zhou, D. (2006). Antecedents and consequences of the strategic orientations in new product development: The case of Chinese manufacturers. Industrial Marketing Management, 35(3), $348-358$.

Jianhong, W., \& Yanxiang, W. (2021). Synthesis analysis for multi-UAVs formation anomaly detection. Aircraft Engineering and Aerospace Technology, 93(1), 180-189.

Kannan, K. S. P. N., \& Garad, A. (2021). Competencies of quality professionals in the era of Industry 4.0: A case study of electronics manufacturer from Malaysia. International Journal of Quality \&amp; Reliability Management, 38(3), 839-871.

Kaparthi, S., \& Bumblauskas, D. (2020). Designing predictive maintenance systems using decision tree-based machine learning techniques. International Journal of Quality \&amp; Reliability Management, 37(4), 659-686.

Kar, A. K., Chatterjee, S., \& Mustafa, S. Z. (2019). Securing IoT devices in Smart Cities of India: From ethical and enterprise information system management perspective. Journal of Enterprise Information System, 15(4), 585-615.

Ketokivi, M. A., \& Schroeder, R. G. (2004). Perceptual measures of performance: Fact or fiction? Journal of Operations Management, 22(3), 247-264.

Ko, T., Lee, J. H., Cho, H., Cho, S., Lee, W., \& Lee, M. (2017). Machine learning-based anomaly detection via integration of manufacturing, inspection and after-sales service data. Industrial Management \&amp; Data Systems, 117(5), 927-945.

Kock, N. (2019). From composites to factors: Bridging the gap between PLS and covariance based structural equation modelling. Information Systems Journal, 29(3), 674-706.

Kraus, M., Feuerriegel, S., \& Oztekin, A. (2020). Deep learning in business analytics and operations research: Models, applications and managerial implications. European Journal of Operational Research, 281(3), 628-641.

Kumar, A., Shankar, R., \& Thakur, L. S. (2018). A big data driven sustainable manufacturing framework for condition-based maintenance prediction. Journal of Computational Science, 27, 428-439.

LeCun, Y., Bengio, Y., \& Hinton, G. (2015). Deep learning. Nature, 521(7553), 436-444.

Li, Z., Wang, W. M., Liu, G., Liu, L., He, J., \& Huang, G. Q. (2018). Toward open manufacturing: A crossenterprises knowledge and services exchange framework based on blockchain and edge computing. Industrial Management \&amp; Data Systems, 118(1), 303-320.

Lin, W. L., Yip, N., Ho, J.-A., \& Sambasivan, M. (2020). The adoption of technological innovations in a B2B context and its impact on firm performance: An ethical leadership perspective. Industrial Marketing Management, 89, 61-71.

Lindell, M. K., \& Whitney, D. J. (2001). Accounting for common method variance in cross-sectional research designs. Journal of Applied Psychology, 86(1), 114-121.

Liu, H., Tang, T., Luo, J., Zhao, M., Zheng, B., \& Wu, Y. (2020). An anomaly detection method based on double encoder-decoder generative adversarial networks. Industrial Robot. https://doi.org/10.1108/IR09-2020-0200

Lu, X., Wang, S., Kang, F., Liu, S., Li, H., Xu, X., \& Cui, L. (2019). An anomaly detection method to improve the intelligent level of smart articles based on multiple group correlation probability models. International Journal of Crowd Science, 3(3), 333-347.

Makadok, R. (2001). Toward a synthesis of the resource-based view and dynamic-capability views of rent creation. Strategic Management Journal, 22, 387-401.

Malaga, A., \& Vinodh, S. (2021). Benchmarking smart manufacturing drivers using Grey TOPSIS and COPRAS-G approaches. Benchmarking: An International Journal. https://doi.org/10.1108/BIJ-12-20200620

Marzouk, M., \& Zaher, M. (2020). Artificial intelligence exploitation in facility management using deep learning. Construction Innovation, 20(4), 609-624.

Mason, R. B. (2007). The external environment's effect on management and strategy: A complexity theory approach. Management Decision, 45(1), 10-28. 
Mishra, A., Maheswarappa, S. S., Maity, M., \& Samu, S. (2018). Adolescent's eWOM intentions: An investigation into the roles of peers, the Internet and gender. Journal of Business Research, 86, 394-405.

Moorman, C., \& Miner, A. S. (1997). The impact of organizational memory on new product performance and creativity. Journal of Marketing Research, 34(1), 91-106.

Mora Cortez, R., \& Johnston, W. J. (2019). Marketing role in B2B settings: Evidence from advanced, emerging and developing markets. Journal of Business \&amp; Industrial Marketing, 34(3), 605-617. https://doi. org/10.1108/JBIM-04-2017-0089

Murphy, H., \& de Jongh, H. (2011). Student perceptions of information system subject learning in hospitality management degree programmes: A study of contexts for "deep learning." International Journal of Contemporary Hospitality Management, 23(3), 393-409.

Naoui, M. A., Lejdel, B., Ayad, M., Amamra, A., \& Kazar, O. (2021). Using a distributed deep learning algorithm for analyzing big data in smart cities. Smart and Sustainable Built Environment, 10(1), 90-105.

Navas, M. A., Sancho, C., \& Carpio, J. (2020). Disruptive maintenance engineering 4.0. International Journal of Quality \&amp; Reliability Management, 37(6/7), 853-871.

Nazir, A., Mir, R. N., \& Qureshi, S. (2020). Exploring compression and parallelization techniques for distribution of deep neural networks over Edge-Fog continuum-A review. International Journal of Intelligent Computing and Cybernetics, 13(3), 331-364.

Nguyen, B., Ghosh, S. K., Bhattacharjee, K. K., \& Chaudhuri, S. (2020). Adoption of artificial intelligence integrated CRM system: An empirical study of Indian organizations. The Bottom Line, 33(4), 359-375.

Pasi, B. N., Mahajan, S. K., \& Rane, S. B. (2020). The current sustainability scenario of Industry 4.0 enabling technologies in Indian manufacturing industries. International Journal of Productivity and Performance Management. https://doi.org/10.1108/IJPPM-04-2020-0196

Podsakoff, P., MacKenzie, S., Lee, J.-Y., \& Podsakoff, N. (2003). Common method biases in behavioral research: A critical review of the literature and recommended remedies. The Journal of Applied Psychology, 88(5), 879-903.

Podsakoff, P. M., MacKenzie, S. B., \& Podsakoff, N. P. (2012). Sources of method bias in social science research and recommendations on how to control it. Annual Review of Psychology, 63, 539-569.

Porter, C. E., \& Donthu, N. (2006). Using the technology acceptance model to explain how attitudes determine internet usage: The role of perceived access barriers and demographics. Journal of Business Research, 59(9), 999-1007.

Qayyum, A., Razzak, I., Tanveer, M., \& Kumar, A. (2021). Depth-wise dense neural network for automatic COVID19 infection detection and diagnosis. Annals of Operations Research. https://doi.org/10.1007/ s10479-021-04154-5

Rafiki, A., Hidayat, S. E., \& Al Abdul Razzaq, D. (2019). CRM and organizational performance: A survey on telecommunication companies in Kuwait. International Journal of Organizational Analysis, 27(1), 187-205.

Rana, N. P., Chatterjee, S., \& Dwivedi, Y. K. (2020). Social media as a tool of knowledge sharing in academia: An empirical study using valance, instrumentality, and expectancy (VIE) approach. Journal of Knowledge Management, 24(10), 2531-2552.

Rana, N. P., Chatterjee, S., Dwivedi, Y. K., \& Akter, S. (2021). Understanding dark side of artificial intelligence (AI) integrated business analytics: Assessing firm's operational inefficiency and competitiveness. European Journal of Information Systems. https://doi.org/10.1080/0960085X.2021.1955628

Rezaei, M., Jafari-Sadeghi, V., Cao, D., \& Amoozad Mahdiraji, H. (2021). Key indicators of ethical challenges in digital healthcare: A combined Delphi exploration and confirmative factor analysis approach with evidence from Khorasan province in Iran. Technological Forecasting and Social Change, 167, 120724.

Salah Sobh, T. (2013). Anomaly detection based on hybrid artificial immune principles. Information Management \&amp; Computer Security, 21(4), 288-314.

Sarstedt, M., Ringle, C. M., Henseler, J., \& Hair, J. F. (2014). On the emancipation of PLSSEM: A commentary on Rigdon (2012). Long Range Planning, 47(3), 154-160.

Schmidhuber, J. (2015). Deep learning in neural networks: An overview. Neural Network, 61, 85-117.

Schuberth, F., Henseler, J., \& Dijkstra, T. K. (2018). Partial least squares path modeling using ordinal categorical indicators. Quality and Quantity, 52(1), 9-35.

Shahin, A., Aminsabouri, N., \& Kianfar, K. (2018). Developing a decision making grid for determining proactive maintenance tactics: A case study in the steel industry. Journal of Manufacturing Technology Management, 29(8), 1296-1315.

Shoham, A., Rose, G. M., \& Kropp, F. (2005). Market orientation and performance: A metanalysis. Marketing Intelligence and Planning, 23(5), 435-454.

Silbernagel, C., Aremu, A., \& Ashcroft, I. (2020). Using machine learning to aid in the parameter optimisation process for metal-based additive manufacturing. Rapid Prototyping Journal, 26(4), 625-637. 
Smith, K., \& Lovgren, R. (2018). Empirical evidence of deep learning in learning communities. Journal of Applied Research in Higher Education, 10(3), 311-321.

Song, M., Droge, C., Hanvanich, S., \& Calantone, R. (2005). Marketing and technology resource complementarity: An analysis of their interaction effect in two environmental contexts. Strategic Management Journal, 26(3), 259-276.

Sreenivasulu, N. S., \& Chatterjee, S. (2019). Personal data sharing and legal issues of human rights in the era of artificial intelligence: Moderating effect of government regulation. International Journal of Electronic Government Research, 15(3), 21-36.

Teece, D., Pisano, G., \& Shuen, A. (1997). Dynamic capabilities and strategic management. Strategic Management Journal, 18(7), 509-533.

Teece, D. J. (2012). Dynamic capabilities: Routines versus entrepreneurial action. Journal of Management Studies, 49(8), 1395-1401.

Thakur, R., Angriawan, A., \& Summey, J. H. (2016). Technological opinion leadership: The role of personal innovativeness, gadget love, and technological innovativeness. Journal of Business Research, 69(8), 2764-2773.

Tiddens, W., Braaksma, J., \& Tinga, T. (2020). Exploring predictive maintenance applications in industry. Journal of Quality in Maintenance Engineering. https://doi.org/10.1108/JQME-05-2020-0029

Torres, D., Pimentel, C., \& Duarte, S. (2020). Shop floor management system in the context of smart manufacturing: A case study. International Journal of Lean Six Sigma, 11(5), 837-862.

Voorhees, C. M., Brady, M. K., Calantone, R., \& Ramirez, E. (2016). Discriminant validity testing in marketing: An analysis, causes for concern, and proposed remedies. Journal of the Academy of Marketing Science, 44, 119-134.

Wakiru, J., Pintelon, L., Muchiri, P., \& Chemweno, P. (2021). A data mining approach for lubricant-based fault diagnosis. Journal of Quality in Maintenance Engineering, 27(2), 264-291.

Wamba, S. F., Dubey, R., Gunasekaran, A., \& Akter, S. (2020). The performance effects of big data analytics and supply chain ambidexterity: The moderating effect of environmental dynamism. International Journal of Production Economics, 222, 107498.

Wamba-Taguimdje, S.-L., Fosso Wamba, S., Kala Kamdjoug, J. R., \& Tchatchouang Wanko, C. E. (2020). Influence of artificial intelligence (AI) on firm performance: The business value of AI-based transformation projects. Business Process Management Journal, 26(7), 1893-1924.

Wang, H., Czerminski, R., \& Jamieson, A. C. (2021). Neural networks and deep learning. In M. Einhorn, M. Löffler, E. de Bellis, A. Herrmann, \& P. Burghartz (Eds.), The machine age of customer insight (pp. 91-110). Emerald. https://doi.org/10.1108/978-1-83909-694-520211010

Wong, W. P., Tan, K. H., Govindan, K., Li, D., \& Kumar, A. (2021). A conceptual framework for informationleakage-resilience. Annals of Operations Research. https://doi.org/10.1007/s10479-021-04219-5

Wu, H., Shen, G., Lin, X., Li, M., Zhang, B., \& Li, C. Z. (2020). Screening patents of ICT in construction using deep learning and NLP techniques. Engineering, Construction and Architectural Management, 27(8), 1891-1912.

Xiao, Q., Wang, R., Sun, H., \& Wang, L. (2020). Objective evaluation of fabric pilling based on image analysis and deep learning algorithm. International Journal of Clothing Science and Technology. https://doi.org/ 10.1108/IJCST-02-2020-0024

Xie, X., Lu, Q., Rodenas-Herraiz, D., Parlikad, A. K., \& Schooling, J. M. (2020). Visualised inspection system for monitoring environmental anomalies during daily operation and maintenance. Engineering, Construction and Architectural Management, 27(8), 1835-1852.

You, M.-Y. (2017). A predictive maintenance system for hybrid degradation processes. International Journal of Quality \&amp; Reliability Management, 34(7), 1123-1135.

Young, R., \& Jordan, E. (2008). Top management support: Mantra or necessity? International Journal of Project Management, 26(7), 713-725.

Youssef, Y. M. A., Johnston, W. J., AbdelHamid, T. A., Dakrory, M. I., \& Seddick, M. G. S. (2018). A customer engagement framework for a B2B context. Journal of Business \&amp; Industrial Marketing, $33(1), 145-152$.

Zwikael, O. (2008). Top management involvement in project management: Exclusive support practices for different project scenarios. International Journal of Managing Projects in Business, 1(3), 387-403.

Publisher's Note Springer Nature remains neutral with regard to jurisdictional claims in published maps and institutional affiliations. 